\title{
Deformite cerrahisi komplikasyonları ve tedavisi
}

\author{
Complications and their treatment of deformity correction
}

\author{
Mustafa Uysal \\ Sakarya Üniversitesi Tıp Fakültesi, Ortopedi ve Travmatoloji Anabilim Dalı, Sakarya
}

\begin{abstract}
Deformite cerrahisinde olgular çoğu zaman komplike ve tedavi süreci uzundur. Bu nedenle planlama, cerrahi işlem ve takip süreçlerinde titiz davranılmalıdır. Deformite cerrahisinde tüm prensiplere uyulmasına rağmen tedavi sürecinde çeşitli komplikasyonlar ile karşılaşmak olasıdır. Bu durum çoğu zaman tedavinin seyrini değiştirmez ve ufak müdahaleler ile üstesinden gelinebilir. Bazı komplikasyonlar ise tedavinin seyrini etkiler ve tedavi süresini uzatır. Bazı ciddi komplikasyonlar ise tedaviyi olumsuz etkiler ve hem süresini uzatır hem sonucunu olumsuz etkiler. Bu açıdan bakıldığında komplikasyonları genel olarak majör ve minör olarak ikiye ayırmak mümkündür. Tedavinin hangi aşamasında hangi komplikasyonlar ile karşılaşabileceğimizi bilmemiz bize avantaj sağlar. Bu durumda komplikasyonları oluş sırasına göre cerrahi tedavi sırasında oluşanlar, erken ve geç komplikasyonlar olarak üç grup altında inceleyebiliriz. Komplikasyonları bilmek kadar onları nasıl tedavi edeceğimizi de bilmek önemlidir. Komplikasyonlarla mücadelede en önemli husus uygun ve zamanında müdahaledir. Bu amaçla ameliyat öncesi hasta ve yakınlarını da bilinçlendirmek ve uyumunu sağlamak önemlidir. Komplikasyonlara karşı uyanık olmak ve onlarla mücadele yollarını bilmek deformite cerrahisine başarıya giden yolda çok işimize yarayacaktır. Bununla birlikte bu konudaki bilgi ve tecrübe arttıkça komplikasyon görülme riski azalacaktır.
\end{abstract}

Anahtar sözcülkler: deformite; cerrahi; komplikasyon; tedavi
Most of cases in deformity surgery are complicated and demands long time period for treatment. Therefore, surgeon have to be meticulous in planning, surgery and follow-up phases. Although all the principles of the deformity surgery are precisely followed, it is possible to encounter various complications during the treatment process. The course of treatment generally is not effected and a minor intervention is sufficient. Some of complications effect the course of treatment and prolong the treatment. Some serious complications effect the outcome and change both result and duration of treatment. In this respect, it is possible to divide the complications into major and minor complications. It is an advantage for us to know which complications we may encounter at which stage of treatment. In this case, all complications can be classified into three groups as early and late complications. It is important to recognize the complications as well as how to treat them. Correct intervention in the right time is most important in the fight against complications. For this reason, it is crucial to inform patients and their relatives before surgery and to guarantee their cooperation. Being on alert and having ability to fight against complications are most powerful tools on the way of success. The risks of complication will decrease as well as our knowledge and experience in deformity surgery increase in time.

Key words: deformity; surgery; complication; treatment

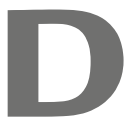
eformite cerrahisinde ister eksternal fiksator sistemleri veya bilgisayar destekli sistemler, ister motorize çiviler, ister kombine metotlar kullanalım ve yahut çivi veya plak sistemleri ile akut düzeltmeler yapalım; hangi metodu kullanırsak kullanalım komplikasyonlar bazen tedavinin seyri sırasında kaçınılmaz olarak karşımıza çıkan istenmeyen durumlardır. Oluşan komplikasyonlar şiddetine göre tedavinin seyrini olumsuz etkileyerek kimi durumlarda tedavinin sonucunu bile etkileyebilirler. Deformite cerrahisinde tedavi sürecinin uzun ve vakaların çoğu kez komplike olmasından dolayı birçok komplikasyon ihtimalinin olması göreceli olarak bu cerrahi ile uğraşmak isteyenlerin hevesini kırıcı olabilir. Fakat ekstremite deformitelerinin giderilmesinin sağladığı fonksiyonel kazançlar nedeniyle bunlar oldukça göze alınabilir durumlardır. Bu açıdan bakıldığında risklerin farkında olup, komplikasyonlardan kaçınmaya çalışmak veya oluşabilecek komplikasyonlara zamanında müdahale edecek bilgi ve beceriye sahip olmak uygulanan tedavinin başarısını olumlu yönde etkileyecektir.

- Illetişim adresi: Prof. Dr. Mustafa Uysal, Sakarya Üniversitesi Tıp Fakültesi Ortopedi ve Travmatoloji Anabilim Dalı, Sakarya Tel: 0532 - 3708006 e-posta: mstfysl@hotmail.com

- Geliş tarihi: 6 Aralık $2019 \quad$ Kabul tarihi: 7 Şubat 2020 
Genel olarak komplikasyonları, tedavilerinin ek bir cerrahi müdahale ile sağlanmasının gerekli olup olmamasına göre majör ve minör olarak ikiye ayırabiliriz. ${ }^{[1]}$ Dahl komplikasyonları hafif, orta, şiddetli olarak sınıflarken risk faktörlerini büyük küçük olarak ayırmıştır. [2] Ayrıca komplikasyonları derecelendirerek gruplandırmak bir başka uygulamadır. ${ }^{[1-4]}$ Popkov ise farklı olarak komplikasyonları kemikle ilgili, eklemle ilgili, enfeksiyöz ve nörovasküler olarak ayırmıştır. ${ }^{[5]}$ Paley'in geliştirdiği sınıflamaya göre ise tüm istenmeyen durumlar problem, engel ve komplikasyon olarak sınıflandırılmıştır. ${ }^{[6]}$ Paley'e göre problemlerin tedavisinden cerrahi bir müdahaleye gerek duymazken, engellerin tedavisinde ise ufak cerrahi müdahalelere ihtiyaç duyulabilir. Komplikasyonlar ise lokal veya sistemik olabilir ve tedavi sonrasında kalıcıdırlar. Ana cerrahinin amacına ulaşmasına engel olup olmamasına göre komplikasyonlar majör ve minör olarak ikiye ayrilırlar. Tedavi sonrasında devam eden komplikasyonların giderilmesi cerrahi müdahale ile mümkün oluyorsa minör, olmuyor ve sekel oluşmuşsa majör komplikasyon olarak adlandırılır.

Deformite cerrahisinde komplikasyonlar tedavinin başladığı operasyon anından tedavi sonlandırılıktan sonraki geç takip dönemlerine kadar geniş bir zaman diliminde karşımıza çıkabilir. Bu komplikasyonları genel olarak görülme zamanına göre ayırırsak: Cerrahiye bağlı komplikasyonlar, erken ve geç komplikasyonlar olarak sınıflandırabiliriz.

\section{CERRAHIYE BAĞLI KOMPLIKASYONLAR}

\section{Damar-Sinir Lezyonları}

Operasyon sırasında pinlerin (çivilerin) ve tellerin geçirilmesi esnasında olabileceği gibi kortikotomi veya osteoklazi işlemleri sırasında da görülebilir. Cerrah uygulama sırasında bu yaralanmalardan kaçınmak için kesitsel anatomiyi iyi bilmek zorundadır. Bunun için uygulamaya yönelik anatomi atlaslarından yararlanılarak ameliyat öncesi planlamada pin ve teller için ekstremite segmentine ait güvenli aralıkların belirlenmesi gerekir. Kolun distalinde ve önkolun proksimalinde radial sinir, el bileği seviyesinde radial sinirin duyu dalı, fibula boynu seviyesinde peroneal sinir, tibia proksimalinde anterior tibial arter en sık yaralanan yapılardır. Arter ve venin beraber yaralanması durumunda fistül oluşumu gözlenebilir. Minor damar yaralanmalarından sonra lokal tamponad yapılması genellikle kanamayı durdurur. Sonrasında dikkatli dolaşım takibine alınması gerekir. Major damar ve sinir yaralanmalarından kaçınmak amaçlı telin yaratacağı ısı ve mekanik etkileri azaltmak için kemik korteksi geçildikten sonra yumuşak doku içinde tel, motor kullanılmadan ilerletilmelidir. Sinir yaralanmalarından kaçınmak için anestezi uzmanından kas gevşetici ajanlar kullanmaması istenmelidir. Bu şekilde refleks kas kasılmalarını gözlemlemek ve şüpheli durumlarda telin yerini değiştirmek mümkün olur. Özellikle önkol distalinde pin ve tel gönderilmeden önce radial sinirin ufak bir insizyondan diseke edilerek korunması komplikasyondan kaçınmak için yardımcı olacaktır.

\section{Kompartman Sendromu}

Damarsal yapıların yaralanması ile olabileceği gibi travma sırasında zedelenmiş kompartmalardan çok sayıda pinlerin geçilmesi ile kompartman basınçnın arttırılmasıyla da oluşabilir. Osteotomiler sonrası hematom oluşumu kompartman basıncını arttırabilir. Büyük damar yaralanması sonrası veya kanama şüphesi olması durumlarında profilaktik olarak fasyatomi planlanabilir. Şüphede kalındığında ise kompartman içi basınç ölçülerek takip edilmelidir.

\section{Yetersiz Kortikotomi}

Daha çok drilleme ile yapılan minimal invaziv osteotomilerde karşımıza çıkar. Uzatma yapılması planlanan vakalarda kortikotominin tüm kemik korteksini içerecek şekilde yapılamamasından dolayı operasyon sonrası planlanan distraksiyon sağlanamaz. Tedavi süresinin uzaması ve ağrı gibi sorunlara yol açar. İkinci bir operasyonla kortikotominin tamamlanması ile sorun çözülebilir. Kortikotomi sonrasında skopi yardımı ile fragmanlar arası translasyonun sağlandığı kontrol edilmelidir.

\section{ERKEN KOMPLIKASYONLAR}

\section{Tel veya Pin (Çivi) Dibi Enfeksiyonu}

En sık görülen komplikasyondur. ${ }^{[7-10]}$ Bazı serilerde \%96'ya varan oranda bildirilmiştir. ${ }^{[8]}$ Deri yüzeyinden başlayıp içerilere doğru ilerler. Cilt irritasyonundan selülite, cilt altı enfeksiyonuna, derin yumuşak doku ve kemik enfeksiyonuna doğru seyir izler. Tel dibi enfeksiyonu; tel gerginliği, cilt gerginliği, kemik ve cilt arasındaki yumuşak dokunun miktarı gibi etkenlerle yakından ilişkilidir. ${ }^{[11]}$ Çoğu zaman cilt dokusunun tel etrafındaki hareketi ile oluşan irritasyon ile tetiklenir (Şekil 1). Bunu engellemek için tel üzerine sarılan tamponların cilde yakın tutmak amacıyla plastikten veya köpükten yapılmış bastırıcılar kullanılabilir. Ameliyat sırasında veya uzatma sırasında telin veya pinin cilt üzerinde oluşturduğu gerilimin engellenmesi gerekmektedir. Bunun için ameliyat sırasında frame (çerçeve) tespiti yapılırken cilde dikkat edilmesi, gerekirse bistüri yardımı ile gevşetilmesi önerilir. ${ }^{[7]}$ Tel dibi enfeksiyonlarının tedavisinde erken teşhis ve müdahale önemlidir. Bu yüzden hasta ve yakınları tel dibi 


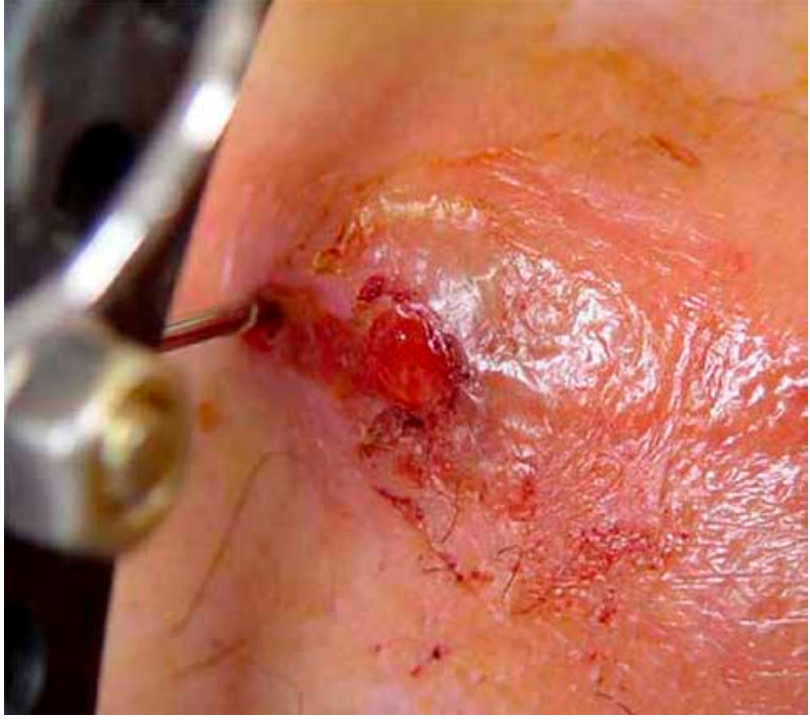

Şekil 1. Pin (çivi) dibi enfeksiyonu (Grade 2).

bakımı konusunda eğitilmeli ve enfeksiyon konusunda uyarılmalıdır. Her çeşit enfeksiyon ağrılı uyaran oluşturacağından fizik tedavi sürecini olumsuz etkileyecektir. Çeşitli sınıflamalar arasında daha basit olduğu için Paley'in tarif ettiği sınıflamayı buraya alacağım. ${ }^{[6]}$ Bu sınıflamaya göre tel dibi enfeksiyonları şiddetine göre üç derecede incelenir. Grade 1: Yüzeyel yumuşak doku enflamasyonudur. Tel gerginliği kontrol edildikten sonra uygun antiseptik solüsyonla tel dibi temizliği ve baskılı pansuman ile genellikle bir günde gerilerler. Grade 2: Derin yumuşak doku enfeksiyonudur. Kemiğe ulaşmamıştır. Antibiyoterapi ile bir haftada kontrol altına alınabilir. Grade 3: Kemik enfeksiyonudur. Tedavisi daha zordur. Pin veya telin çıkarılması ve lokal debridman gerekir.

\section{Eklem Kontraktürleri}

Teorik olarak kemik istenilen miktarda uzatılabilir; fakat kasların gerilme kabiliyetleri sınırlıdır. Eklem kontraktürleri sıklıkla uzatma cerrahilerinde özellikle fleksör grup kasların kemik uzamasına uyum gösterememesi sonucu gelişen temel sorunlarından birisidir. Uzama sırasında antagonistik hareketi yaptıran kasların yapıları arasındaki farklılıklardan dolayı eklem kontraktür yönüne doğru zorlanır. Tespitin tendon içinden veya kasın liflerinden zengin dokuların içinden geçilerek yapılması kasın uyumunu güçleştirir. Alt ekstremitede diz, ayak bileği ve ayak parmaklarında, üst ekstremitede dirsek, el bileği ve el parmaklarında sıklıkla fleksiyon kontraktürü şeklinde görülebilir.

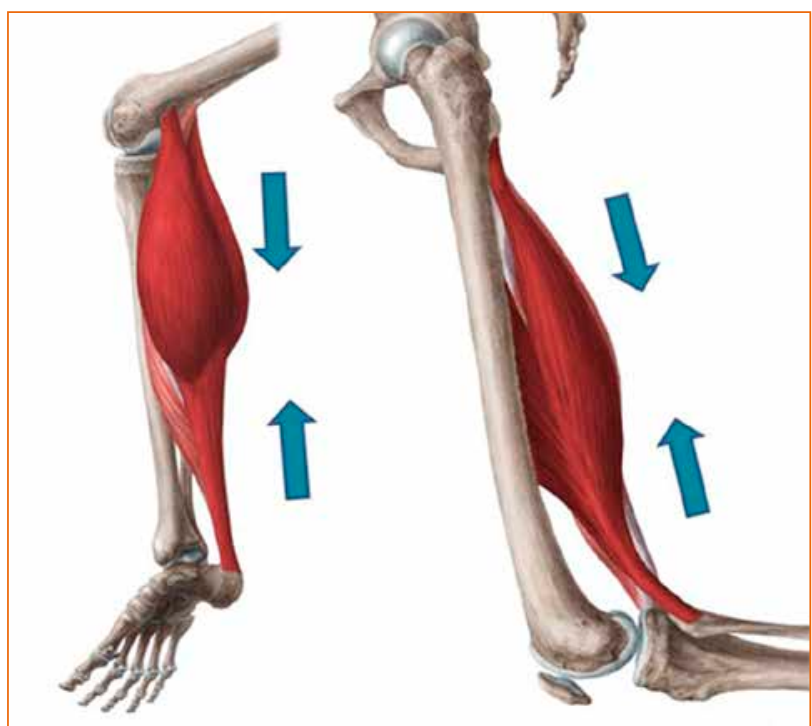

Şekil 2. Uyluk ve bacakta gastroknemius ve hamstring grubu kasların kontraktür oluşumuna katkılarının gösterilmesi.

Her iki eklemi geçen kaslar tek eklemi geçen kaslara göre farklı uzunlukta kas lifleri içerdiğinden uzatma sırasında kas içi farklı gerilim kuwvetleri oluşur (Şekil 2). Bu kasın rejenerasyonunu diğer kaslara göre farklı etkiler. Bu nedenle hamstring grubu ve gastrokinemius kaslarının etkisi ile diz ve ayak bileği fleksiyon kontraktürleri daha sık görülür. ${ }^{[6,12]}$ Bunun için ekleme yakın tespitlerin bu kasların boyunun maksimum uzunluğu sağlanacak gerginlikte yapılması önerilir.

Kontraktürün önlenmesinde düzenli ve sık fizik tedavi egzersizlerinin rolü büyüktür. ${ }^{[13,14]}$ Pasif germe en sık başvurulan yöntemdir. Dizi ekstansiyonda, ayak bileğini $90^{\circ}$ fleksiyonda tutan frame (çerçeve) ile uyum gösteren istirahat ateli uygulamaları kontraktürün ilerlemesinin engellenmesine yardımcı olur. [15] Buna rağmen eklem kontraktürlerinin ilerlediği durumlarda $\left(>40^{\circ}\right)$ eklem frame (çerçeve) içine dahil edilerek tedrici düzeltme uygulanabilir. Bazı durumlarda da kontraktür oluşumunun önüne geçmek için uzatma ritmi yavaşlatılabilir veya durdurulabilir. Çok sık kullanılmayan diğer bir metod ise ekstremitenin hedeflenenden $10 \mathrm{~mm}$ daha fazla uzatılıp sonra tekrar kısaltılmasıyla yumuşak dokulardaki gerginliğin önüne geçilmesidir. Özellikle tibiada $6 \mathrm{~cm}$ üzeri yapılacak uzatmalarda eklemlerin cerrahi sırasında tespite dahil edilmesi ve uzatma bitince çıkarılması önerilmektedir. ${ }^{[6]}$

Bununla birlikte tenotomi, miyotomi ve tenoplasti gibi işlemler olası kontraktür gelişimini önleyici önlemlerdir. Özellikle femoral uzatmalarda rektus 


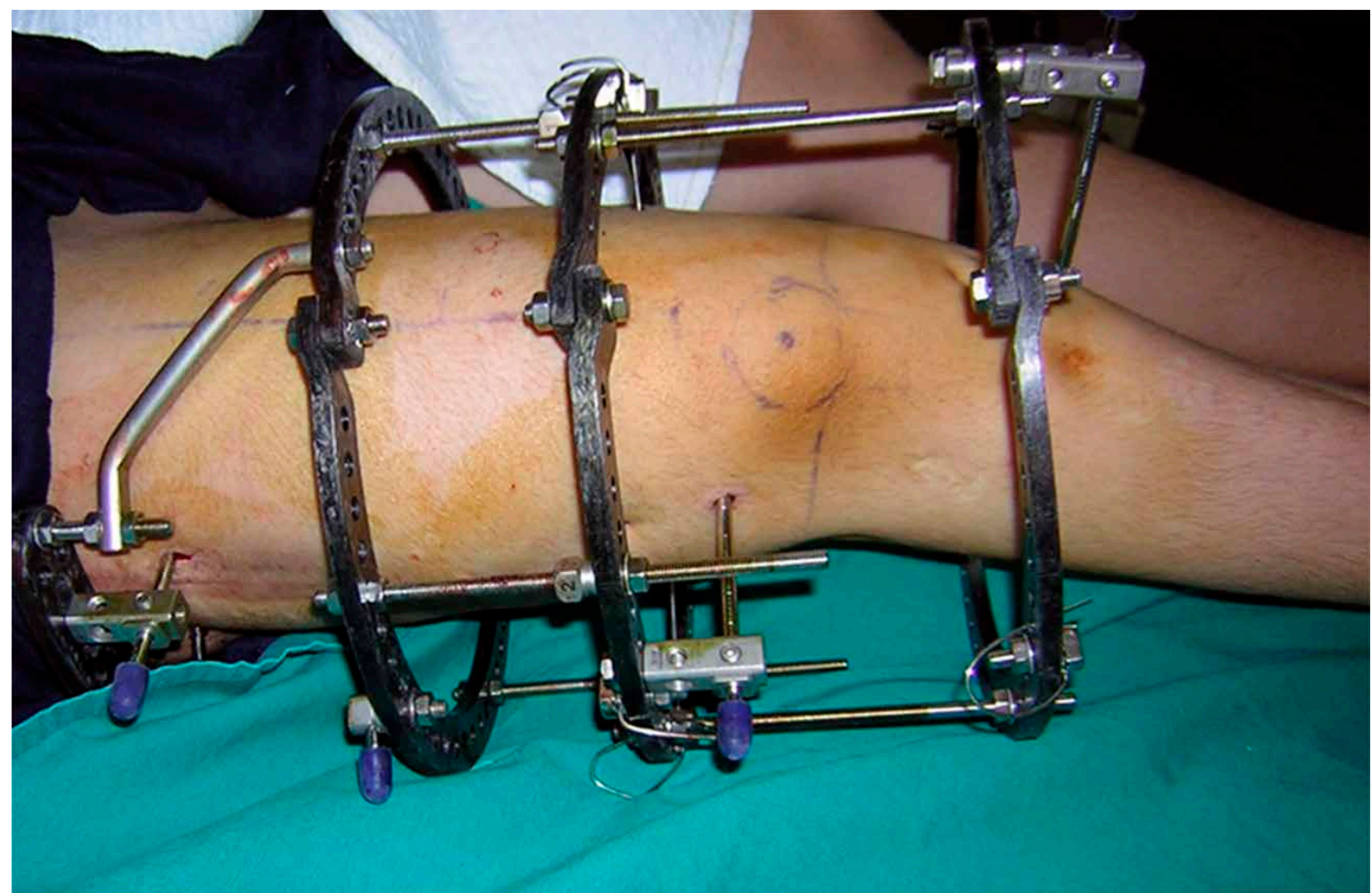

Şekil 3. Konjenital (doğumsal) femur kısalığı nedeniyle femoral uzatma planlanan ve diz eklemi instabilitesi bulunan hastanın, uzatma süresince subluksasyon riskine karşı diz eklemin tek halka yardımıyla tespit edilmesi.

femoris, fasia lata, sartorius ve hamstring kaslarının uzatılması, tibial uzatmalarda aşiloplasti uygulamaları sıklıkla başvurulan yöntemlerdir. Eklem kontraktürü, hasta memnuniyetsizliğini en fazla arttıran etkenlerdendir. Bu yüzden koruyucu tedbirlerin alınması önemlidir.

\section{Nörolojik Semptomlar}

Sinir dokusunun gerilime verdiği cevaptır ve diğer dokulara göre daha yavaştır. Bu nedenle sinir dokusunun gerilime cevabı kemik uzama hızını belirleyen faktörlerin başlıcasıdır. Bu cevap kendini çoğunlukla nöropraksi olarak belli eder ve fark edilmezse paraliziye dönebilir. İlk semptomlar ağrı ve hiperestezidir. Sonrasında hipoestezi ve kuvvet kaybı olur. ${ }^{[16]} \mathrm{Bu}$ nedenle takiplerde duyu ve motor kuvvet kontrolü önemlidir. Belirtiler ortaya çıtı̆̆ında uzatma durdurulur veya geriye dönülür. En sık peroneal ve tibialis posterior sinirleri etkilenir. Riskleri azaltmak için aşırı düzeltme veya uzatma yapılacaksa önceden peroneal sinirin veya tarsal tünelin gevşetilmesi koruyucudur. Gerilmeye bağlı semptomlar erken yakalandığında kendiliğinden düzelebilirler. Nörolojik hasarın bulunduğu durumlar ileride kontraktür gevşetme veya tendon transferi gibi cerrahiler gerektirebileceğinden ciddi komplikasyonlardandır.

\section{Eklem Subluksasyonları}

En sık oluşum sebebi, hastanın eklem instabilitesine yatkın durumda olmasıdır. ${ }^{[17]}$ Konjenital femur kısalığ (proximal femoral focal deficiency) ve fibular hemimeli gibi bazı doğumsal hastalıklar bu duruma örnek verilebilir. En sık diz olmakla birlikte kalça ve ayak bileği eklemlerinde de görülebilir. ${ }^{[17]}$ Kas gruplarının kuvvetli çekim etkisi ile ihmal edilen eklem kontraktürleri sonrası oluşabilir. ${ }^{[18]}$ Femoral uzatmada, hamstring kas grubu tendonlarının tibiayı arkaya çekmesi ile dizde posteriora subluksayon görülebilir. Öngörülen durumlarda eklemin tespite dahil edilebilmesi önleyici olabilir (Şekil 3). Tedavisinde tedrici olarak distraksiyonla birlikte redüksiyon denenebilir. Gerekirse yumuşak doku gevşetmeleri yapılmalıdır.

Asetabular displazinin belirgin olduğu (CE [merkez kenar açısı $]<20^{\circ}$ ) femoral uzatma vakalarında kalça subluksasyonu riski bulunmaktadır. Öncesinde kalça eklemi örtünmesini arttıracak operasyonlar koruyucu 


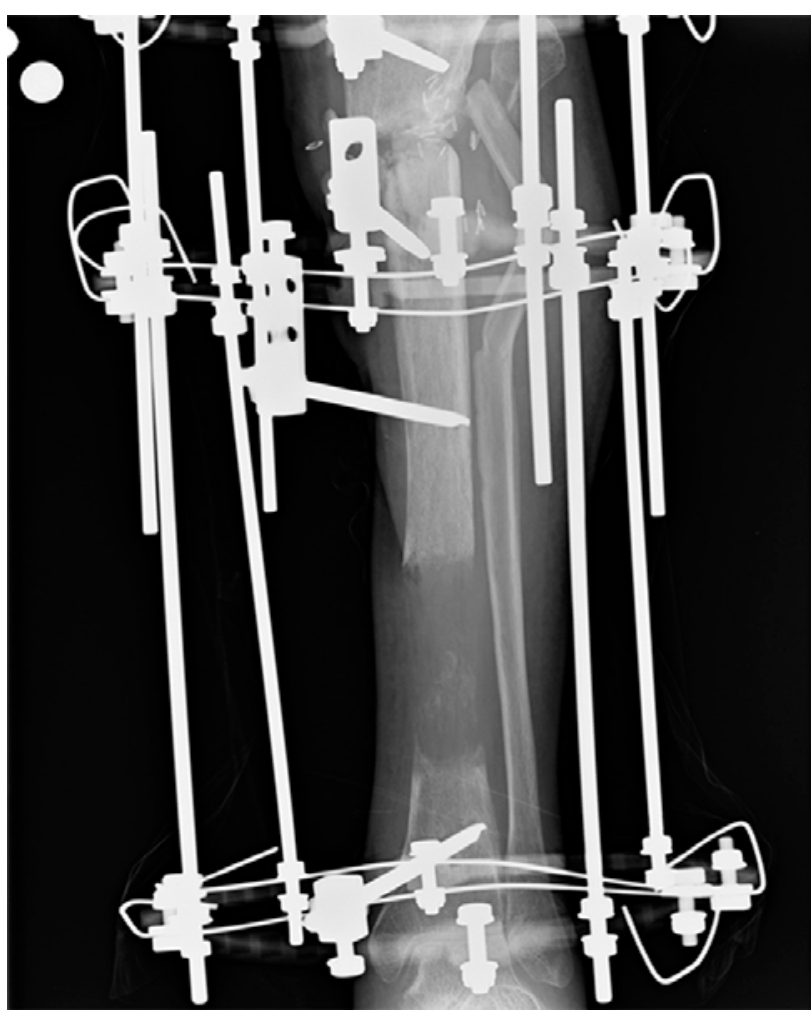

Şekil 4. Kemik uzatma sonrası yeni oluşan yetersiz rejenerat dokusu.

olabilir. Eklem subluksasyonunun ciddi olduğu bazı durumlarda ise açık redüksiyon gerekli olabilir.

\section{Erken Kaynama veya Gecikmiş Konsolidasyon}

En sık femur ve fibulada görülür. Konsolidasyon safhasına geçilmeden planlanandan önce kaynamanın oluşmasıdır. Genellikle latent periyodun uzun tutulması ile oluşur. Çocuklar için önerilen süre femurda beş, tibiada yedi gündür. Erişkinlerde bu süre duruma göre uzatılır. Fibuladaki erken kaynamanın önüne geçmek için kortikotomi yerine açık osteotomi yapmak uygundur. Ağrı ve aşırı yüklenmeden dolayı tellerdeki eğilme ile kendini belli eder. Tedavisinde kortikotominin yenilenmesi gerekebilir.

Bunun tam tersi gecikmiş konsolidasyondur. En sık sigara içilmesi ve metabolik hastalıklarla birlikte görülmesine rağmen malnutrisyon, hızlı distraksiyon, kısa latent periyod, $4 \mathrm{~cm}$ üzeri uzatmalar, travmatik kortikotomi, aynı bölgeden daha önce geçirilmiş operasyonlar, frame instabilitesi ve akut deformite düzeltmesi gibi durumlar risk taşır. ${ }^{[19]}$ Diafizyal kortikotomilerde metafizyel olanlara göre daha sıktır. Kontrollerde çekilen düz grafilerde yetersiz rejenerat görülmesi ile tanı konulur (Şekil 4). Distraksiyon yavaşlatılır veya durdurulur. Hasta ekstremite üzerine yük vererek yürümesi konusunda cesaretlendirilebilir. Bir veya daha çok kompresyon-distraksiyon uygulaması diğer bir seçenektir. ${ }^{[20]}$ Rejeneratın uyarılamadığı durumlarda otojen kemik greftlemesi gerekebilir.[21]

\section{Yeni Deformite Gelişimi}

Çoğu zaman segmentlerin yetersiz tespiti veya tel gerginliklerindeki yetersizliklere bağlı mekanik nedenler altta yatar. Konsolidasyon bölgesine binen asimetrik kuvvetler zamanla ekstremite ekseninde bozulmaya neden olabilirler. Uzama miktarı arttıkça deformasyon riski artar. Anatomik özelliklerinden dolayı proksimal femur ve distal tibia varusa ve prokurvasyona doğru, proksimal tibia ise valgus ve prokurvasyona doğru gitmeye meyillidir. Bu doğrultularda engelleyici zeytinli teller ve Schanz çivileri kullanılırsa sorunun önüne geçilebilir. Ayrıca femur distalinde ve tibia proksimalindeki halkaların deformite oluş yönünün aksi doğrultusunda $5^{\circ}-10^{\circ}$ açı ile sisteme tespit edilmesi önlem olarak uygulanabilir.

$5^{\circ}$ 'ye kadar olan hafif deformiteler asimetrik kompresyon veya distraksiyon ile çözülebilirken, $5^{\circ}-10^{\circ}$ arası olanlar frame (çerçeve) revizyonuna ihtiyaç duyarlar. $10^{\circ}$ 'den fazla olan deformiteler ise deformite planlaması sonrasında menteşeli sistemlerle tedavi edilirler (Şekil 5).

\section{Ağrı}

Ağrının hissi kişiye bağıı olarak değişiklik gösterebilir. Güncel cerrahi yaklaşımlar ve analjezi protokolleri ile ciddi bir sorun teşkil etmemesine rağmen ağrı tek başına veya diğer sorunlarla birlikte olabildiğinden çok sık karşılaşılan bir semptomdur. Ağrı genellikle periostun gerilmesi, kas spazmı, kontraksiyonlar ve tellerin yarattığı yumuşak doku enflamasyonu ile olur. Özellikle uzatma sırasında gerilimin yarattığı ağrı tedavinin seyrini etkileyebilir. ${ }^{[22]}$ Ağrının neden olduğu hareket kısıtıılığ; kontraktür ve dolaşım sorunlarını oluşturabilir. Kişinin ağrı eşiğine uygun dozda medikasyon uygulanmalı, hafiflemediği durumlarda sebebe yönelik araştırma yapılmalıdır.

Ekstremitede şişlik erken dönemde cerrahi lokal travmaya daha sonrası ise hareketlerde azalmaya sonucu venöz dönüş yetersizliğine bağlı oluşabilir. Ağrının ve şişliğin fazla olduğu durumlarda refleks sempatik distrofi gelişme olasılığı akılda tutulmalıdır. Elevasyon önerilir. Frame (Çerçeve) çıktıktan sonra genellikle geriler. Aşırı ödem durumlarında nadiren frame (çerçeve) revizyonu gerektirir. 


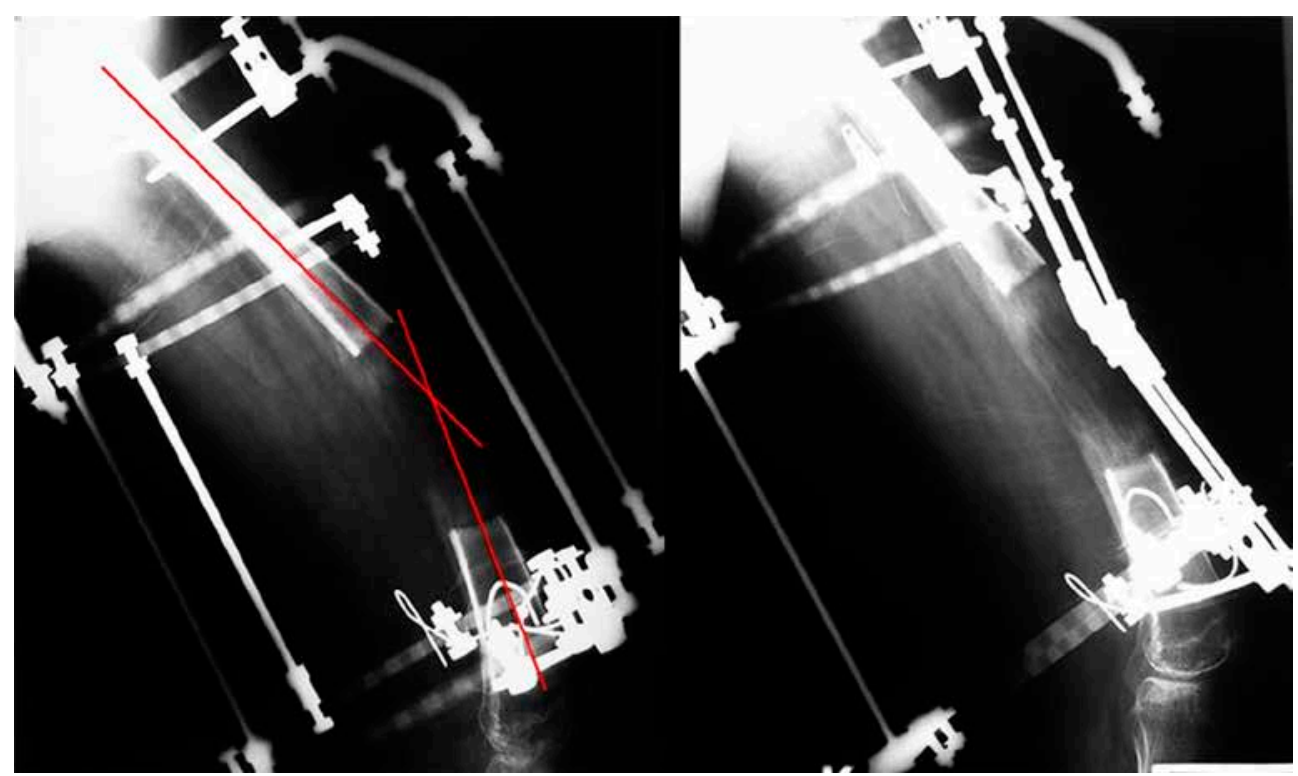

Şekil 5. Uzatma sırasında femurda $30^{\circ}$ 'nin üzerinde prokurvatum deformitesi gelişmesi üzerine menteşe sistemi eklenerek deformitenin düzeltilmesi.

Tedavi sırasında tel veya pin (çivi) üzerine aşırı gerilim kuvvetinin binmesi sonucu metal yorgunluğuna bağlı implant yetmezliği oluşabilir. Kemiğe veya halkaya yakın en zayıf noktadan kırılma oluşur. Ani başlayan ağrı ile kendini belli eder. Tel gerilimleri kontrol edilmesi ve direkt grafi ile kesin tanı konulur (Şekil 6). Kırılan parçalar çıkarılmalı, yeni tel veya pin tespiti yapılmasına sistemin stabilite ihtiyacına göre karar verilmelidir.

\section{GEÇ KOMPLIKASYONLAR}

Yeni deformite gelişmesi, refraktür ve eklem sertliği çoğunlukla tedavi sonlandırıldıktan sonra görülen geç komplikasyonlardandır.

Yeni deformite oluşumu ve refraktür çoğunluklar yetersiz rejenerat oluşumuna bağlı olarak oluşur. Konsolidasyon süresinin kısa tutulmasına bağlı kemik iyileşmesinin tam olmamasından dolayı cihaz çıkarıldıktan sonra zayıf olan kemik doku bükülerek deformite oluşturabilir veya kırılabilir. Önlemek için frame (çerçeve) çıkarılmadan önce konsolidasyon bölgesinde ön ve yan direkt grafilerle üç korteksin oluştuğu kontrol edilmelidir. ${ }^{[23]}$ Önlem olarak bağlantı rodları gevşetilerek frame (çerçeve) dinamizasyonu yapılabilir. Çocuklarda ve konjenital (doğumsal) vakalarda önlem olarak frame (çerçeve) çıktıktan sonra koruyucu breys uygulaması yapılmalıdır. Refraktür ayrıca artmış arteryal kan akımına, kullanmamaya veya refleks sempatik distrofiye bağlı osteoporoz nedeniyle farklı seviyelerden stres kırığı şeklinde olabilir.
Hedef uzunluğa ulaşmada 5 mm'nin içinde kalan farklar başarılı sayılırken, üzeri aksiyel deformiteler komplikasyon olarak değerlendirilmelidir. ${ }^{[24]}$ Genel olarak 20 mm'nin üzerindeki kısalıklar kabul edilebilir sınırların üzerindedir ve ek cerrahi tedavi gerektiren majör komplikasyonlardandır. Kırık sonucunda $5^{\circ}$ 'den az olması minör, fazla olması majör komplikasyondur. ${ }^{[6]}$

Eklem sertliği kontraktürden farklı daha ciddi bir komplikasyondur. Eklem hareket açıklığının büyük

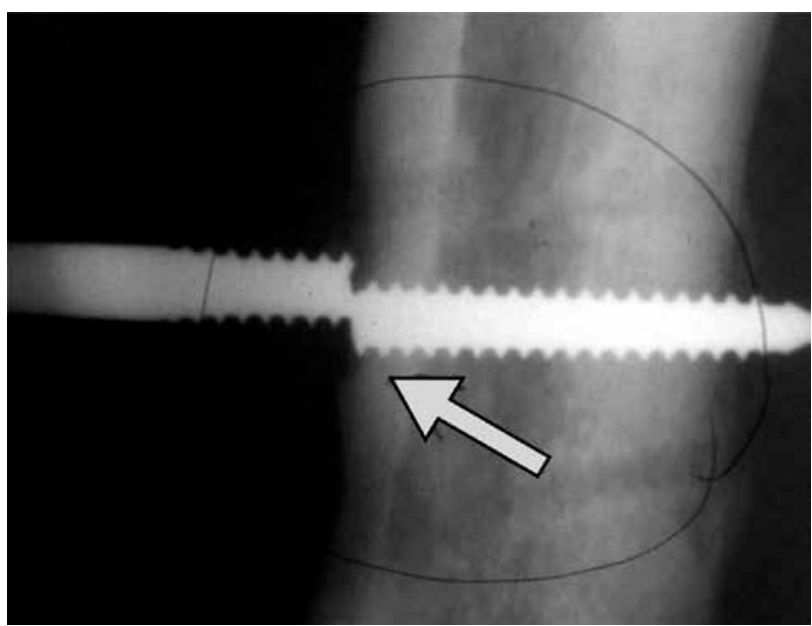

Şekil 6. Schanz çivisinin kemiğe girdiği yerden kırılması. 
oranda azalması ile kendini gösterir. Frame (Çerçeve) hasta üzerinde iken düzeltilemeyen eklem kontraktürleri geç dönemde eklem sertliğine dönüşebilir. Artrofibrozis, kas kontraktürleri eklem kıkırdak hasarı eklem sertliğine eşlik edebilir. Eklem kıkırdağına aşırı yük bindiği durumlarda kıkırdak harabiyeti durumu daha sıkıntılı bir hale sokar. Ciddi komplikasyonlardandır. Hasta memnuniyetini çok olumsuz etkiler. Ekleme distraksiyon uygulayarak tedrici düzeltmeler veya geniş yumuşak doku gevşetmeleri kısıtlı tedavi seçenekleri arasındadır.

\section{Öneriler}

Deformite cerrahisinde başarı, deformite prensiplerini doğru uygulamak kadar komplikasyonlardan kaçınmak ile mümkün olur. Bu nedenle deformite ile uğraşmak isteyen hekimin bu riskleri bilmesi, önlem alması ve gerekli müdahaleleri zamanında yapabilmesi gerekmektedir. Öncelikli hasta uyumu çok önemlidir. Hasta ameliyat öncesi dönemde kendisine yapılacak tedaviyi iyice kavramış, ortalama tedavi süresini, kendisini bekleyen tedavi aşamalarını ve risklerini kabullenmiş olmalıdır. Hasta komplikasyon ihtimallerine karşı bilgilendirilmeli ve gerekli durumlarda doktoruna başvurabilir yakınlıkta bulunmalıdır. Ayrıca kendisinin fark edemediği durumlar için takiplerini düzenli doktor kontrollerine gelebilecek durumda olması, hasta ve hasta yakınlarından talep edilmelidir. Hasta eğitimi için cerrahi sonrası dönemde cihazın bakımı ve sık karşılaşılan sorularla ilgili hastaya yazılı, resimli görsel dökümanlar sunmak uyum sürecini hızlandıracaktır. Hasta uyumu başarılı sonuç için ön koşullardan birisidir. Örneğin sigaranın İlizarov ile rekonstrüksiyon uygulanan hastalarda komplikasyon riskini arttırdığının bilinmesine ${ }^{[25]}$ rağmen kemik uzatma planlanan bir hastanın tedavisi sırasında sigara içmeye devam etmesi yeterli uyumun sağlanamaması olarak yorumlanabilir.

Deformite cerrahisindeki başarı bir takım çalışmasını ayrıca gerektirmektedir. Bu takımda genel olarak doktor, hasta, hasta yakınları, fizyoterapist, radyolog ve yara-bakım görevlileri bulunur. Bu kişiler arasındaki koordinasyon çok önemlidir. Bu dengenin cerrahi öncesi kurulması ve işletilmesine dikkat edilmelidir.

Her ne kadar komplikasyonlardan kaçınmak istense de bu her zaman mümkün olmaz. Cerrahi tecrübe sadece cerrahi uygulamadaki beceriyi değil komplikasyonlara zamanında ve uygun müdahale edebilmeyi gerektirir. Bununla birlikte komplikasyon görülme oranının zamanla cerrahın tecrübesi arttıkça azaldığı gösterilmiştir. ${ }^{[2]}$

Deformite cerrahisi prensiplerine uygun yapılmış cerrahilerin komplikasyonları yanında hastalara sağladığı yararlar tartışmasızdır. Bu alanda başarı deformite prensiplerinin doğru uygulanarak oluşabilecek komplikasyonlar hakkında bilinçli olunması ve bunların tedavisi ile ilgili bilgi ve tecrübe birikimine sahip olunması ile sağlanır.

\section{KAYNAKLAR}

1. Velazquez RJ, Bell DF, Armstrong PF, Babyn P, Tibshirani R. Complications of use of the Ilizarov technique in the correction of limb deformities in children. J Bone Joint Surg Am 1993;75(8):1148-56. Crossref

2. Dahl MT, Gulli B, Berg T. Complications of limb lengthening. A learning curve. Clin Orthop Relat Res 1994;(301):10-8. Crossref

3. Caton J. Traitment des inegalites de longeur des membres inferieurs et des sujets de petite taille chez l'enfant et l'adolecent. Rev Chir Orthop 1991;77(Suppl 1):31-80.

4. Vargas Barreto B, Caton J, Merabet Z, Panisset JC, Pracros JP. Complications of Ilizarov leg lengthening: a comparative study between patients with leg length discrepancy and short stature. Int Orthop 2007;31(5):587-91. Crossref

5. Popkov A. Erors and complications of operative lengthening of the lower extremities in adults by the llizarov method. Vestn Khir Im I Grek 1991;146(1):113-6.

6. Paley D. Problems, obstacles, and complications of limb lengthening by the Ilizarov technique. Clin Orthop Related Res 1990;(250):81-104. Crossref

7. Eralp L, Kocaoglu M, Bilen FE, Balci HI, Toker B, Ahmad K. $A$ review of problems, obstacles and sequelae encountered during femoral lengthening: uniplanar versus circular external fixator. Acta Orthop Belg 2010;76(5):628-35.

8. Antoci V, Ono CM, Antoci V Jr, Raney EM. Pin-tract infection during limb lengthening using external fixation. Am J Orthop (Belle Mead NJ) 2008;37(9): E150-4.

9. Eldridge JC, Bell DF. Problems with substantial limb lengthening. Orthop Clin North Am 1991;22(4):625-31.

10. Garcia-Cimbrelo E, Olsen B, Ruiz-Yagüe M, Fernandez-Baíllo N, Munuera-Martínez L. Ilizarov technique. Results and difficulties. Clin orthop Relat Res 1992;(283):116-23. Crossref

11. Green SA, Ripley MJ. Chronic osteomyelitis in pin tracks. J Bone Joint Surg Am 1984;66(7):1092-8. Crossref

12. Damsin JP, Ghanem I. Treatment of severe flexion deformity of the knee in children and adolescents using the Ilizarov technique. J Bone Joint Surg Br 1996;78-B(1):140-4. Crossref

13. Acharya A, Guichet JM. Effect on knee motion of gradual intramedullary femoral lengthening. Acta Orthop Belg 2006;72(5):569-77.

14. Herzenberg JE, Scheufele LL, Paley D, Bechtel R, Tepper S. Knee range of motion in isolated femoral lengthening. Clinical Orthop Relat Res 1994;(301):49-54. Crossref

15. Kocaoglu M, Eralp L, Kilicoglu O, Burc H, Cakmak M. Complications encountered during lengthening over an intramedullary nail. J Bone Joint Surg Am 2004;86-A(11):240611. Crossref

16. Young NL, Davis RJ, Bell DF, Redmond DM. Electromyographic and nerve conduction changes after tibial lengthening by the Ilizarov method. J Pediatr Orthop 1993;13(4):473-7. Crossref

17. Jones DC, Moseley CF. Subluxation of the knee as a complication of femoral lengthening by the Wagner technique. J Bone Joint Surg Br 1985;67-B(1):33-5. Crossref 
18. Suzuki S, Kasahara Y, Seto Y, Futami T, Furukawa K, Nishino Y. Dislocation and subluxation during femoral lengthening. J Pediatr Orthop 1994;14(3):343-6. Crossref

19. Kenawey M, Krettek C, Liodakis E, Meller R, Hankemeier S. Insufficient bone regenerate after intramedullary femoral lengthening: risk factors and classification system. Clin Orthop Relat Res 2011;469(1):264-73. Crossref

20. Kocaoglu M, Eralp L, Sen C, Cakmak M, Dincyürek $H$, Göksan SB. Management of stiff hypertrophic nonunions by distraction osteogenesis: a report of 16 cases. J Orthop Trauma 2003;17(8):543-8. Crossref

21. Wagner $\mathrm{H}$. Operative lengthening of the femur. Clin Orhop Relat Res 1978;(136):125-42. Crossref
22. Young N, Bell DF, Anthony A. Pediatric pain patterns during Ilizarov treatment of limb length discrepancy and angular deformity. J Pediatr Orthop 1994;14(3):352-7. Crossref

23. De Bastiani G, Aldegheri R, Brivio LR, Trivella G. Limb lengthening by callus distraction (callotasis). J Pediatr Orthop 1987;7(2):129-34. Crossref

24. Burghardt RD, Herzenberg JE, Specht SC, Paley D. Mechanical failure of the Intramedullary Skeletal Kinetic Distractor in limb lengthening. J Bone Joint Surg Br 2011;93-B(5):639-43. Crossref

25. McKee MD, DiPasquale DJ, Wild LM, Stephen DJG, Kreder $\mathrm{HJ}$, Schemitsch EH. The effect of smoking on clinical outcome and complication rates following llizarov reconstruction. J Orthop Trauma 2003;17(10):663-7. Crossref 